\title{
Evaluation of Good Manufacturing Practices in Small Dairy Plants in Jordan
}

\author{
Gharaibeh A. Ahmad* \\ Department of Food Science and Nutrition, Faculty of Agriculture, Jerash University, P.O.Box 311, Jerash \\ 26110, Jordan
}

\begin{abstract}
The aim of this study was to assess the good manufacturing practices (GMPs) in small dairy plants in Jordan. In addition, the microbial product quality was used to assess the quality control practices in the production of concentrated yogurt (Labanah). The study was applied to 40 small dairy plants in the governorates of Irbid and Jerash, north of Jordan. Data were collected using a questionnaire, which consisted of a general information section besides two sections that addressed GMPs and the barriers to implementation of GMPs in the small dairy plants in Jordan. Assessment of GMPs was performed by using a structured questionnaire (checklist) that consisted of four sub-sections that addressed contemplating building, personnel, equipment, and food production. The mean overall score of implementation of GMPs in Irbid was 2.75, meaning that implementation of GMPs was low to moderate, while in Jerash it was 2.14, suggesting a low level of implementation of GMPs. Results showed that poor infrastructure and lack of financial resources were the most prominent obstacles to implementation of GMPs in the sample dairy plants in both governorates. The mean total counts of bacteria in the Labanah samples collected from the 40 dairy plants were 4.36 and $6.8 \log _{10} \mathrm{cfu} / \mathrm{mL}$, respectively. All the Labanah samples showed negative results of salmonella and staphyllocccus. Contamination of the Labanah samples with yeast and molds, and coliform bacteria was an indicator of insufficient hygienic practices. Implementation of the food safety practices by the dairy producers is necessary.
\end{abstract}

Keywords: Food safety, Labanah, Microbiological quality.

DOI: $10.7176 / F S Q M / 84-05$

\section{Introduction}

The dairy products play an important role in the Jordanian diet. They are the lowest-price source of animal proteins. In addition, they contribute highly to subsistence of a wide number of producers and families in the peri -urban and rural areas (AOAD, 2003). As such, the dairy industry plays an important role in the economy of Jordan. In other respects, the dairy factories can be classified into modern dairy factories, manual dairy factories, and home processing factories. In Jordan, there are 25 modern factories and hundreds of small dairy plants scattered around the country, particularly in the northern governorates, especially Irbid and Jerash.

The basic food safety system consists of a combination of good manufacturing practices (GMPs), good hygiene practices (GHPs), and of the Hazard Analysis and Critical Control Point (HACCP) system. The GMPs are the basis of Prerequisite Programs (PRPs), which are the procedures that control the conditions of food processing. The general measures of GMP as described by Codex Alimentarius_include hygiene in the primary production, hygienic design of equipment and facilities, control of operations, maintenance and sanitation practices, personal hygiene, transportation, product information, and consumer awareness and training (Codex, 2003). In developing countries such as Jordan, shortcomings in the food safety performance of dairy-processing organizations have been attributed to outdated and poorly-designed equipment, inadequate sanitation programs, restricted personal hygiene, and low numbers of skilled employees. The successive governments of Jordan have made several attempts to improve the safety and standards of milk production and processing. In 2003, the government modified the legislation that regulates and controls food and drug production, importing, and use and assigned the related responsibilities to the Jordanian Food and Drug Administration (JFDA), which is one of the directorates of the Jordanian Ministry of Health. This administration applies a_documented, formal risk assessment method suggested by the Codex Alimentarius Commission (CAC).

Dias (2012) found that the percentage of conformities of building and facilities in the mozzarella cheeseprocessing plant before and after implementation of GMPs based on the basic requirements established by Codex Alimentarius and Brazillian legislation were $43 \%$ and $64 \%$, respectively. Nowicki (2016) mentioned that the barriers, constrains, and difficulties hindering compliance of enterprises to Food Safety Management Systems (FSMSs) may be in general categorized as financial, infrastructure, and people-related constrains.

The dairy product Labanah is defined as a semi-solid product obtained from yogurt and which is concentrated by the draining of whey and water-soluble compounds. Labanah is made from cow, goat, or sheep milk. In the last five years, numerous studies reported on the microbial and chemical qualities of Labanah. For example, the total bacterial count in unbranded samples ranged from $5 \times 10^{7} \mathrm{cfu} / \mathrm{mL}$ to $3 \mathrm{X} \mathrm{cfu} / \mathrm{mL}$ (Gharaibeh, 2017). Somer and Golden (2012) found that the mean number of colony-forming units of yeast and mold in the Labanah ranged from $1.4 \times 10^{6}$ to $1.3 \times 10^{7} \mathrm{cfu} / \mathrm{mL}$. Although several studies of the microbiological and physiochemical qualities of 
Labanah have been carried out, to the researcher's best knowledge only few studies investigated implementation of the GMPs in the dairy plants. Therefore, the objectives of this study were to assess the level of implementation of GMPs in small dairy plants in Jordan, evaluate compliance of these plants with food safety standards, and identify the barriers and difficulties these plants face during implementation of the GMPs and related standards.

\section{Materials and methods}

Screening interviews were held with students from the Food Science and Nutrition Department, Jerash University, prior to design of the questionnaire during several training visits to large and small dairy plants. The surveys employed questionnaire (checklist) and face-to-face interviews with plant managers or owners. Design of the questionnaire was based on the information obtained from the screening interviews, regulations of the Jordanian Food and Drug Administration (JFDA 2015) related to the dairy product factories, and the available literature (e.g., Bas, et al., (2007) and Ibarra, (2014)). Based on this information, a questionnaire consisting of three parts was developed. The three parts addressed general information, level of implementation of GMPs, and barriers to implementation of GMPs.

\subsection{Characteristics of the dairy plants and Labanah}

The general information section was included in the questionnaire to rank the participants in the survey. It included four questions that inquired about the types of products produced in the factory, number of the employees in the factory, level of education of the respondent, and age of the factory.

The researcher randomly selected 40 small dairy plants from two governorates in the north of Jordan (Irbid and Jerash) based on that these two governorates contained the majority of the small-scale dairy plants in the country (109 and 40 dairy plants, respectively). These dairy plants consisted of 34 microenterprises $(<10$ employees) and 6 small-medium enterprises (SMEs), each having 11-49 employees. None of these dairy plants had used HACCP or other quality assurance (QA) standards in their Food Safety Management Systems (FSMSs). In fact, these plants were still using simple food production technologies. The main equipment available were simple stainless steel or plastic buckets to transfer and/or incubate milk, cooling tanks, batch pasteurizers, incubators, and hand-operated pouch-sealing machines. The main dairy products which these plants produce are milk, yogurt, concentrated yogurt (Labanah), cheese, and gameed, which is a fermented dairy product produced either as stone-hard balls or thick liquid. The concentrated yogurt (Labanah) is a semi-sold dairy product with $23 \%$ total solids, $9 \%$ fats, and $1-2 \%$ salt. The titrable acidity of Labanah may lies within the range of $1.8-2 \%$ as lactic acid and its shelf life under refrigeration conditions is 14 days (JISM, 2003). Production of Labanah in Jordan is carried out by either the traditional or mechanical methods. In both methods, yogurt is produced from pasteurized milk and yogurt starter according to the standard procedure of yogurt manufacture. According to the traditional method, the desired concentrated Labanah is obtained after removing the whey by straining the yogurt gel in Muslin cloth bags (usually $50 \times 70 \mathrm{~cm}$ bags) which are hung in refrigerator for 18-20 hr to allow for drainage of the whey (Ozer et al., 1997). In this respect, several methods have been developed to produce Labanah with a similar composition as the traditional product such as ultra-filtration of normal yogurt, fermentation of the milk concentrated by reverse osmosis, reverse osmosis treatment of normal yogurt, and centrifugal separation of the whey from the normal yogurt (Robinson and Tamime, 1993).

\subsection{Assessment of GMPs}

The second part of ther questionnaire probed the sample members' perceptions of, and opinions about, implementation of GMPs in the plants in which they work. The respondents were informed to express their levels of agreement with the questions related to the level of implementation of each GMP on a numerical scale ranging from 1 to $5(1=$ very low, $2=$ low, $3=$ moderate, $4=$ high, and $5=$ very high $)$. The GMPs of interest addressed four facets: building and facilities, equipment and utensils, personnel, and food production. The third part of the questionnaire consisted of 10 questions that address the barriers to implementation of GMPs in the sample plants from the view points of the plant managers.

\subsection{Microbial analysis}

The samples of strained yogurt (Labanah) produced from cows' milk were purchased from 20 vendors in Irbid and Jerash, sent directly to the laboratory, and kept under refrigeration $\left(2-4{ }^{\circ} \mathrm{C}\right)$ until analysis, which was carried out in the last day of the shelf life period (14 days) recorded by the producers. Each analysis was performed in duplicate. Microbial counts were estimated using different media, depending on the target microbes. In specific, the total bacterial counts were estimated on Nutrient Agar (NA (Oxoid)) for the total coliform bacteria. The violet-red blood agar (VRBA (Oxoid)) was used. The Baired-Parker agar (BPA) was used to estimate the total staphylococci (oxoid) and the Salmonella Chromogenic Agar (SCA (Hi Media)) was used to estimate Salmonella. Lastly, the yeast and molds were grown on potato dextrose agar (PD (Hi Media)). Microbial counts (colony-forming units $\left[\log _{10} \mathrm{cfu} / \mathrm{g}\right]$ ) were carried out using the methodologies recommended by the JFDA laboratories. 


\subsection{Statistical Analysis}

Microsoft Excel was used to prepare tables of data on the variables of the study in order to quantify the qualitative responses. The collected data were analyzed by using Microsoft Excel to obtain descriptive statistics of means and standard deviations. The mean, minimum, and maximum scores were calculated for the levels of agreement of the respondents with the questionnaire items related to the levels of implementation of GMPs in the sample dairy plants as well as for the overall scores.

\section{Results and Discussion}

\subsection{General Characteristics of the Sample Dairy Factories and Employees}

The general data collected were the types of dairy products produced by each sample plant, number of employees in each plant, education levels of the plant managers, and plant age. The results (Table 1) show that all the sample plants produce yogurt and Labanah. The results also uncover that $52.5 \%$ of the sample plants have less than 5 employees, $32.5 \%$ of the study plants have 6 to 10 employees, and $15 \%$ of the plants have more than 10 employees (Table 1). The majority of the managers $(92.5 \%)$ have a high school certificate or less, while $7.5 \%$ have a university degree. Most of the factories (62.5\%) are 6 to 10 years old.

\subsection{Levels of Implementation of Good Manufacturing Practices (GMPs)}

Table 2 shows the levels of implementation of GMPs in the sample dairy plants on a scale from 1 to $5(1=$ very low, 2 = low, 3 = moderate, $4=$ high, and $5=$ very high). The GMPs of interest to this study were categorized into four major areas: building construction and layout, personnel, equipment and utensils, and production and process control. The overall mean score for the level of implementation of GMPs of the dairy plants in Irbid was 2.75, corresponding to low to moderate implementation level. Meanwhile, the GMP implementation level was low in Jearsh since the overall mean score was 2.14. The GMP with moderate level of implementation in both Irbid and Jerash was temperature/time control, with mean scores of 3.6 and 3.3, respectively. To the contrary, the least implemented GMP was documentation and keeping of records, with mean scores of 1.9 and 1.6, respectively. According to the regulations of JFDA (2003), the building and surrounding of the food-manufacturing plant must be kept well protected against contamination, i.e., the walls, floors, and ceiling should be easy to clean; the doors and windows are fitted with net or screen; and the building of the plant is adequately lighted and ventilated. Moreover, there should be an adequate supply of potable water, the drainage system should be well designed around and within the plant, and a perfect pest control system should be available.

Bas et al., (2006) highlighted that a well-designed layout for the food facilities and equipment is very important for eliminating and preventing hazards. Dias (2012) found that the percentage of conformities of building and facilities in the mozzarella cheese-processing plant before and after implementation of GMPs based on the basic requirements established by Codex Alimentarius and the Brazillian legislation were 43\% and 64\%, respectively. Cusato et al., (2013) reported that the conformity (\%) of building and facilities of the dairy industry in terms of GMPs was $80 \%$ and that the main non-conformities were related to flies and to residues from the plant effluent exposed to the environment. Kahindi (2016) found that more than $75 \%$ of their sample food establishments cleaned and maintained their internal and external areas and that only $37 \%$ of the food establishments had restroom facilities with adequate ventilation.

The current study also found that the mean scores of implementation of GMPs in personnel hygiene and health in Irbid and Jerash were 2.85 and 2.0, respectively. According to JFDA legislations, in order to conform to good personnel hygiene all laborers should have valid health certificates, the staff should be medically examined once every six months, a policy for personnel habits should be available and in place, and the staff should wear protective clothing, hair covers, and disposable gloves. Bas (2007) found that in their study sample of 339 food businesses only $20.9 \%$ of the food production managers implemented the personnel hygiene practices, $56.3 \%$ have basic personnel hygiene training, and $93 \%$ of the directors did not have hygienic practice manual. Cusato et al., (2013) reported that the 'food handlers' item was the GMP item of the highest conformity (85.7\%). Kahindi (2016) found that only $38 \%$ of the food establishments trained the food handlers appropriately to control hazards, which caused limited food safety knowledge among the employees and managers.

Equipment and utensils are tools used in processing, holding, transferring, and filling. The GMP requires appropriate design of equipment and utensils to prevent corrosion, building up of materials, or adulteration with lubricants. Moreover, it stresses cleaning and sanitizing portable equipment and storing of utensils to avoid splash, dust, and other contamination (Somwang, et al., 2013). As in this study,_Kurwijila and Bennett, (2011) corroborated that the majority of the dairy plants with small-scale production were often using non-hygienically designed equipment and building and simple food production technologies such as batch pasteurization and fermentation and manual packet filling and sealing. In contrast, Tomasevic, et al., (2016) found that cleaning and sanitation, personal hygiene, equipment maintenance, pest control, and water and temperature control, together with traceability, were practiced by almost all the Serbian dairy plants.

Production and process control refers to control of the raw production materials, temperature/time, and 
storage and transportation, as well as documentation and keeping of records. Raw materials, in a process sample, and finished products are tested to identify what they are and determine their compliance with specifications of physical and chemical properties and standards for microbial and chemical contamination (Somwang, et al., 2013). The results of the present study confirm that the majority of the sample dairy plants lacked structured documentation and systematic registration of data. Similar results were reported by Cusato et al., (2013), where the item 'record keeping' had the lowest level of conformity. Based on these results, the food safety legislation is not enough for ensuring food safety in the dairy industry in Jordan. Technical and educational support should be given to the staff of the dairy firms by different authorities so as to establish a suitable food safety infrastructure.

\subsection{Barriers to implementation of Good Manufacturing Practices}

The dairy byproducts are considered to be of major risk to human health. Thus, implementation of GMPs and other safety measures became mandatory. However, a series of limitations on implementation of those practices and standards started to appear, especially among the small-scale producers. In this context, Table 3 shows the most prominent barriers that prevent implementation of GMPs in the sample dairy plants as identified by the present study. Lack of financial resources proved to be the most prevalent barrier as $95 \%$ of the sample plants in both Irbid and Jerash governorates indicated. The least prevalent barrier in both governorates is the lack of governmental support as indicated by $30 \%$ of the sample plants. A review of food safety literature indicates that success in implementing FSMS is dependent on a complex mix of managerial, organizational, and technological factors. Barriers and obstacles to implementation of FSMS vary from country to country and even from sector to sector within the same country; the small-medium enterprises (SMEs) may feel that the difficulties of implementing FSMS are potentially insurmountable. Several studies illustrated that most of the barriers are more directly or indirectly related to the costs associated with implementation of FSMS and which may not be recouped in short time. Bas (2007) indicated that lack of personnel training $(91.3 \%)$ and the financial cost $(88.7 \%)$ were the most prominentt barriers to implementation of HACCP and ISO 22000. The cost of adopting HACCP was the primary barrier for $46.4 \%$ of a sample of Turkish dairy plants (Karaman et al., 2012) and $26 \%$ of a sample UK plants (Mensah and Jullien 2011). Moreover, Ibarra (2014), investigated implementation of FSMS in Ecuador dairy plants and found that the major barriers were the lack of government support $(40 \%)$, inadequate number of employees in the processing plant (30\%), and lack of trained personnel $(20 \%)$. Tomasevic et al (2016) found that the major difficulty encountered during HACCP implementation in the Serbian dairy industry was associated with the attitude/motivation of the production staff, followed by retention of the production and managerial staff.

\subsection{Microbiological Analysis of Labanah}

The quality of Labanah is governed by a number of factors, aminly the milk quality and the hygienic conditions. Outcomes of assessment of the microbiological quality of the Labanah samples obtained from vendors in Irbid and Jerash are shown in Table 4. The mean total aerobic plate counts were $4.36 \pm 1.45$ and $6.8 \pm 0.9 \log 10 \mathrm{cfu} / \mathrm{g}$ in Irbid and Jerash, respectively. Microbiological analysis of the Labanah samples showed high levels of total aerobic plate counts, coliform bacteria, and yeast and molds. In the meantime, these samples showed negative results of pathogenic bacteria; Salmonella, and Staphellococcus. Unsanitary conditions prevailing at the time of manufacturing the Labanah resulted in the higher counts of the wild strains of microbes. In addition, these high numbers may be a result of post-process contamination. The transfer of yogurt from the filter bags used for straining to packaging materials, storage sites, and market places may too lead to microbial contamination. Somer and Gulden (2012) found that the counts of the total mesophilic aerobic bacteria (TMAB) in 33 samples of Labanah collected from markets in Turkey were ranging from 6.25 to $8.13 \log _{10} \mathrm{cfu} / \mathrm{g}$. Presence of coliform bacteria in the Labanah was considered as an indicator of poor hygienic conditions and possible contamination with microorganisms of fecal origin. According to the Jordanian standards, count of the total coliform bacteria in the Labanah samples should not exceed $10 \mathrm{cfu} / \mathrm{g}$. However, our study revealed a high number of coliform bacteria in the Labanah samples, both in Irbid and Jerash. The mean total coliform bacteria counts were $0.96 \pm 0.1$ and 2.68 $\pm 0.2 \log _{10} \mathrm{cfu} / \mathrm{g}$ in the Labanah samples brought from Irbid and Jerash, respectively. These high bacteria counts can be an indication of fecal contamination of the water used in the processing in these plants. Somer and Gulden (2012) found high numbers of coliforms, ranging from 5.96 to $6.29 \log _{10} \mathrm{cfu} / \mathrm{g}$, in strained yogurt samples obtained from local markets in Turkey. Moreover, Alshehabi et al., (2015) found that the average counts of the coliform bacteria were $10 \times 9.7 \mathrm{cfu} / \mathrm{mL}$. In contrast, Yamnani and Abu-Jaber (1994) reported that the mean coliform bacteria count in the traditional Labanah was less than $10 \mathrm{cfu} / \mathrm{mL}$.

The results of the current study flow in harmony with the fact that yeast and molds have the ability to grow well in the acidic foods like Labanah. The analysis results show that the yeast and mould counts in the Labanah samples obtained from Irbid and Jerash were $2.84 \pm 0.14 \log _{10} \mathrm{cfu} / \mathrm{mL}$ and $6.18 \pm 0.99 \log _{10} \mathrm{cfu} / \mathrm{mL}$, respectively. Usually, insufficient heat treatment of milk results in high level of fungal contamination in the Labanah. Results of the present study compare with those of Somer and Gulden (2012) who found that the mean yeast and mold counts in strained yogurt produced in small-scale plants in Turkey lied in the range of 6.15 to $7.12 \log 10 \mathrm{cfu} / \mathrm{g}$. 
These researchers explained the high microbial content of their sample strained yogurt by improper pasteurization of milk. An earlier study (Yamani and Abu-Jaber, 1994) investigated the counts of yeasts in Labanah samples obtained from traditional producers in the local market in Jordan. It found that the mean counts of psycrophilic, mesophilic, and thermophilic yeasts were $1.1 \times 10^{7}, 1.4 \times 10^{7}$, and $2.3 \times 10^{6} \mathrm{cfu} / \mathrm{mL}$, respectively. Moreover, Gharaibeh (2017) found that the average yeast and mold counts in branded and unbranded samples varied from 500 to1,000 and from $1 \times 10^{6}$ to $12 \times 10^{6} \mathrm{cfu} / \mathrm{mL}$, respectively. On the other hand, Cusato, et al., (2013) studied the effect of the implementation of HACCP in a small dairy factory on the microbiological quality of yogurt. They found that the counts of yeast and mold, total coliform bacteria, and fecal coliforms before implementation of HACCP were $2.22 \pm 1.12,1.55 \pm 1.17$, and $0.13 \pm 0.43 \log _{10} \mathrm{cfu} / \mathrm{g}$, respectively. However, after the implementation of HACCP the corresponding counts became $1.89 \pm 1.18,1.43 \pm 1.26$, and $0.13 \pm 45 \log _{10} \mathrm{cfu} / \mathrm{g}$, respectively. The high yeast and molds content of the Labanah will produce a bitter taste and rancidity flavor due to the proteolysis and lipolysis activities.

\section{Conclusions}

The overall level of implementation of GMPs in the dairy plants in the governorates of Irbid and Jerash was found to be low to moderate. The study highlighted the main challenges faced in implementation of GMPs by small dairy plants, the most prominent of which are poor infrastructure and lack of financial resources, in addition to difficulties concerning the personnel.

Several indicators can be used to assess the effectiveness of the implementation of GMPs such as microbiological and chemical indicators. The results pertaining to the microbiological safety performance of the sample dairy plants agree with the outcomes related to the levels of implementation of GMPs in terms of the personnel hygiene and cleaning and sanitation in these plants. Based on the results of the present study, it is concluded that the small dairy plants need to lay further emphasis on quality control of the production process and storage of products. The study recommends the dairy plants to consolidate into groups and reinforce their cooperation in order to raise their manufacturing and commercial capabilities. Furthermore, in order to overcome the illegal practices of some dairies, application of FSMS should be encouraged. Doing so will ensure better control of food production and safe food products without any antimicrobial preservative addition. Finally, the study recommends reducing the shelf life of Labanah from 14 to 10 days such that it is consumed before further microbial growth, hence preventing spoilage of the Labanah during storage.

\section{Acknowledgment}

The author expresses his thanks and gratitude to Jerash University.

\section{References}

Alshehabi, M., F. Hamed., and Sayah Abou-Gorrah. 2015. Effect of the type of the starter and inoculation rate on the characteristics labneh made in direct method compared with the traditional method. Syrian Journal of Agriculture Research. 2(2):55-67.

AOAD. 2003. Arab Organization for Agricultural Development. Report on the Development of Dairy Products, Production, Processing, and Marketing for Small-Scale Dairy Farmers. http: // www.aoad . org/eng/Publications.htm.

Bas, M., Ersun, A. S., Kivanc, G. 2006. The evaluation of food hygiene knowledge, attitude and practices of food handlers' in food businesses in Turkey. Food Control 7(4): 317-322.

Bas, M., Yuksel, M., Cavusoglu, T., 2007. Difficulties and barriers for the implementing of HACCP and food safety systems in food businesses in Turkey. Food Control.18:124-130.

Codex Alimentarius. 2003. Recommended international code of practice general principles of hygiene. CAC/RCP 1- 1969, Review 4- 575 2003. Rome: Codex, pp.1-31. 576

Cusato, S., Gameiro. A. H., Corassin, C. H., Santana, A. S., Cruz, A. G. Faria, J. F., de Oliveira, C. F. 2013. Food safety systems in a small dairy factory: Implementation, major challenges, and assessment of systems performances. Foodborne Pathogens and Disease 10 (1): 6-12.

Dias, MAC., SantAna, AS., Cruz, A. G., Faria, J.A. F., Oliveira, CAO., Bona, E. 2012. On the implementation of good manufacturing practices in a small processing unity of mozzarella cheese in Brazil. Food Control 24: 199-205.

Gharaibeh, A., 2017. A comparison study of the microbial, physical and sensory properties of samples of labneh produced at large (industrial) scale and small scale. Food Science and Quality Management. Vol.63: 1-6.

Ibarra, P. V., 2014.Bottlenecks on implementation of food safety regulation for dairy products in Ecuador. Ghent, Belgium: Ghent University, M.Sc. Thesis.

JFDA, Jordanian Food and Drug Administration (2010). Control Annual Report, Amman Jordan.

JFDA, Jordanian Food and Drug Administration. (2015). GMP, Guidelines in Foodstuffs. No. 39.

JISM. Jordanian Institute for Standardization and Metrology (2003). Jordanian Standards for Milk and Milk 
Products- Labneh..JS: 108, Amman, Joedan.

Kahindi, B. B., 2016. Food safety management practices of small industry enterprises in Tanzania. Glasgow, United Kingdom: Western Kentucky University, M.Sc. Thesis.

Karaman, AD. 2012. Food safety practices and knowledge among Turkish dairy businesses in different capacities. Food Control 26(1): 125-132.

Karaman, AD., Cobanoglu, F., Tunalioglu, R., Ova,G. 2012. Barriers and benefits of implementation of food safety management systems among the Turkish dairy industry. Food Control 25(2): 732-739.

Kurwijila, LR., Bennet, A., 2011. Dairy development institutions in East Africa: Lessons learned and options.FAO.

Mensah, L., and Julien, D., 2011. Implementation of food safety management systems in UK.Food Control, 8(22): 1216-1225.

Nowicki, P. 2016. Barriers constraints and benefits derived from food safety management system implementation: A literature review. Polish Journal of Commodity Science 4(49): 13-21.

Ozer, BH., Robinson RK., Grandison As., Bell, AE. 1997. Composition of techniques for measuring the rheological properties of labneh (concentrated yogurt). International Journal DairyTechnology 50: 129-133.

Robinson, RK., Tamime, AY., 1993.Recent Development in Yogurt Manufacture. Modern Dairy Technology. Vol.2. London.UK: Elsevier Applied Sciences pp. 1-35.

Somer,V. F., and Gulden, B. K., 2012. Microbiological, physiological properties and biogenic amine contents of the strained yogurt 647 from Turkish local markets. African Journal of Biotechnology 11(78): 14338-14343.

Tomasevic, I., Smigic, N., Dekic, I., Zaric, V., Tomic, N., Miocinovic, J., Rajkovic, A. 2016. Evaluation of food safety management systems in Syrbian dairy industry. Mljekarstvo/Dairy 66(1): 48-58.

Somwang, C., Charoenchaichana, P., Polmade, M. 2013.Implementation of good manufacturing practice (GMP) system in the poultry industry. A case study of hatching in Saha Farms Co. Ltd, Thailand. International Journal of Humanities and Management Sciences (IJHMS). Vol. 1 (1): 113-115.

WHO. 1996. World Health Organization (WHO Food Additives, Series 37). Toxicological evaluation of certain food additives prepared by the 46th meeting of joint FAO/WHO expert committee on food additives (JECFA), Geneva

Yamani, MI., Abu-Jaber, M. M. 1994. Yeast flora of labneh produced by in-bag straining of cow milk set yogurt. Journal of Dairy Science 77, 3558-3564.

Table 1. General characteristics of dairy factories and employees in the study governorates

\begin{tabular}{|c|c|c|c|}
\hline Characteristic & Frequency & $(\%)$ & ------------------------------- \\
\hline \multicolumn{4}{|l|}{ Product type } \\
\hline Pasteurized milk & 11 & $(27.5)$ & \\
\hline Yogurt & 40 & $(100)$ & \\
\hline Labanah & 40 & $(100)$ & \\
\hline Cheese & 18 & $(45)$ & \\
\hline Hard gameed & 9 & $(22.5)$ & \\
\hline Butter & 4 & $(10)$ & \\
\hline \multicolumn{4}{|l|}{ Number of employees } \\
\hline $2-5$ & 21 & $(52.5)$ & \\
\hline $6-10$ & 13 & $(32.5)$ & \\
\hline$>10$ & 6 & $(15)$ & \\
\hline \multicolumn{4}{|c|}{ Education level of manager } \\
\hline Less than high school & 20 & $(50)$ & \\
\hline High school & 17 & $(42.5)$ & \\
\hline University & 3 & $(7.5)$ & \\
\hline \multicolumn{4}{|l|}{ Company age } \\
\hline$<2$ Years & 2 & (5) & \\
\hline $3-6$ Years & 8 & (20) & \\
\hline $6-10$ Years & 25 & $(62.5)$ & \\
\hline$>10$ Years & 5 & $(12.5)$ & \\
\hline
\end{tabular}


Table 2. Levels of implementation of Good Manufacturing Practices in the dairy plants

\begin{tabular}{|l|l|l|l|l|l|l|l|l|}
\hline & \multicolumn{3}{|c|}{$\begin{array}{c}\text { Irbid } \\
\text { Indicator }\end{array}$} & \multicolumn{3}{|c|}{$\begin{array}{c}\text { Jerash } \\
(N=20)\end{array}$} \\
\hline & Mean & Min. & Max. & SD & Mean & Min. & Max. & SD \\
\hline Infrastructure & 2.8 & 1.0 & 4.0 & 0.95 & 2.05 & 2.0 & 3.0 & 0.51 \\
\hline Water and air quality & 3.1 & 1.1 & 5.0 & 0.97 & 2.65 & 2.0 & 4.0 & 0.75 \\
\hline Waste management & 2.8 & 1.0 & 4.0 & 0.89 & 1.65 & 1.0 & 2.0 & 0.49 \\
\hline Pest control & 2.3 & 1.0 & 4.0 & 0.84 & 2.3 & 1.0 & 3.0 & 0.73 \\
\hline Personnel hygiene and habits & 2.85 & 2.0 & 3.0 & 0.36 & 2.0 & 1.0 & 3.0 & 0.72 \\
\hline Personnel training & 2.4 & 2.0 & 3.0 & 0.50 & 1.8 & 1.0 & 3.0 & 0.53 \\
\hline Cleaning and disinfection & 2.8 & 1.0 & 4.0 & 0.83 & 2.8 & 2.0 & 3.0 & 0.95 \\
\hline Technical and maintenance indicators & 3.3 & 1.0 & 5.0 & 1.13 & 1.7 & 1.0 & 3.0 & 0.57 \\
\hline Control of raw materials & 3.2 & 2.0 & 5.0 & 1.0 & 2.4 & 2.0 & 3.0 & 0.50 \\
\hline Time/Temper & 3.6 & 1.0 & 4.0 & 0.75 & 3.3 & 2.0 & 4.0 & $0 . .65$ \\
\hline Storage and transportation & 2.2 & 1.0 & 4.0 & 0.89 & 1.9 & 1.0 & 3.0 & 0.72 \\
\hline Documentation and registration & 1.9 & 1.0 & 3.0 & 0.64 & 1.6 & 1.0 & 3.0 & 0.6 \\
\hline Overall mean score & 2.75 & & & & 2.14 & & \\
\hline
\end{tabular}

Table 3. Barriers that prevent dairy plants from implementing Good Manufacturing Practices

\begin{tabular}{|l|c|c|}
\hline Barrier & $\begin{array}{c}\text { Irbid }(N=20) \\
N(\%)\end{array}$ & $N(\%)$ \\
\hline Lack of financial resources & $19(95)$ & $19(95)$ \\
\hline Lack of infrastructure & $17(85)$ & $16(80)$ \\
\hline Lack of management support & $15(75)$ & $16(80)$ \\
\hline Staff turnover & $14(70)$ & $15(75)$ \\
\hline Need to hire specialized personnel & $14(70)$ & $14(70)$ \\
\hline Lack of personnel training & $12(60)$ & $12(60)$ \\
\hline Supplier's trust to provide raw material & $11(55)$ & $12(60)$ \\
\hline Insufficiency in FSMS knowledge & $8(40)$ & $7(35)$ \\
\hline Lack of time & $7(35)$ & $7(35)$ \\
\hline Lack of government support & $6(30)$ & $6(30)$ \\
\hline
\end{tabular}

Table 4. Mean microbial counts in Labanah $\left(\log _{10} \mathrm{cfu} / \mathrm{mL}\right)$

\begin{tabular}{|c|c|c|c|c|}
\hline \multirow[b]{2}{*}{ Governorate } & \multirow[b]{2}{*}{$\mathrm{N}$} & Total count & Total coliform bacteria & Yeast and molds \\
\hline & & \multicolumn{3}{|c|}{$\mathrm{cfu} / \mathrm{mL}$} \\
\hline Irbid & 10 & $4.36 \pm 1.45$ & $0.96 \pm 0.1$ & $2.84 \pm 0.14$ \\
\hline Jerash & 10 & $6.8 \pm 0.9$ & $2.68 \pm 0.2$ & $6.18 \pm 0.99$ \\
\hline
\end{tabular}

